\title{
Analysis of Energy Productivity and Determinant Factors: A Case Study of China's Provinces
}

\author{
Michinori Uwasu ${ }^{1}$, Keishiro Hara ${ }^{1}$, Helmut Yabar $^{2}$ \& Haiyan Zhang ${ }^{3}$ \\ ${ }^{1}$ Center for Environmental Innovation Design for Sustainability, Osaka University, Osaka, Japan \\ ${ }^{2}$ Graduate School of Life and Environmental Sciences, Sustainable Environmental Studies, University of \\ Tsukuba, Tsukuba, Japan \\ ${ }^{3}$ Graduate School of Engineering, Osaka University, Osaka, Japan \\ Correspondence: Michinori Uwasu, Center for Environmental Innovation Design for Sustainability, Osaka \\ University, Osaka, Suita, Yamadaoka 2-1, Japan. Tel: 81-6-6879-4150. E-mail: uwasu@ceids.osaka-u.ac.jp
}

Received: March 3, 2012 Accepted: May 1, 2012 Online Published: May 15, 2012

doi:10.5539/jsd.v5n6p1 URL: http://dx.doi.org/10.5539/jsd.v5n6p1

\begin{abstract}
The objective of this paper is to explore the structure of how energy productivity in China's provinces is determined to draw useful energy policy implications for sustainable development. First, energy productivity is decomposed into two attributes; technology; and input factor which is necessary for economic activities such as labor and capital. The paper then estimates energy technology levels as an indicator across provinces in China through 2004 and 2007 using a growth accounting method. The estimation results show that disparity in energy technology level exists across the provinces even after controlling for differences in the contribution of input factor to energy productivity, implying the importance of technology for energy productivity enhancement. We then identify factors that affect the technology level using regression analysis. The regression results indicate that investment in the energy technology and the quality of human and man-made capitals determine the level of energy technology. Furthermore, we show resource abundance and industrial structures affect incentives to make investment, thereby leading to more efficient technology for energy use. Thus, appropriate energy policies including price setting and a better environment for investment is vital to achieve both economic development and energy conservation. The proposed energy productivity analysis system is also applicable to other countries and regions to draw useful implications for policy making.
\end{abstract}

Keywords: China, energy productivity, technology, growth accounting, energy price

\section{Introduction}

China's economic growth has been so rapid in the last decades that its GDP doubled between 2000 and 2007 and during the same period energy consumption increased at almost the same rate as GDP did (NBSC, 2009a; NBSC, 2009b). Given the sharply increasing amount of energy, the Chinese government set the mid-term policy target to quadruple GDP while doubling energy consumption for the period 2000-2020 (i.e., 50\% improvement in energy intensity), which was indeed achieved in the period 1980-2000. However, as have been observed in some major provinces, the actual growth of GDP and energy consumption appears much faster than the pace envisioned in such policy targets and achieving the policy target is not an easy task in China under the current conditions of business as usual scenario (Hara et al., 2011). Given also the fact that per capita Gross Domestic Products in China is far below the OECD countries' level (World Bank, 2010), achieving both energy conservation and economic growth is therefore an imperative challenge that China faces.

Studies that deal with balancing energy conservation and economic development fall into two groups. The first one looks into causal relationship between economic outcomes (i.e., GDP) and energy consumption. These studies primarily found the causal effects among energy inputs and GDP output, concluding the significance of 1) improving energy efficiency and 2) building sufficient energy supply capacity (He et al., 2008; Yuan et al., 2008; Feng et al., 2009). The other group focuses on the decomposition of energy productivity, a ratio of economic output and energy use, at the country or industry level, which shows that the change in energy efficiency is attributed to 1) growth in energy intensive industries, 2) technological progress in energy use, and 3) rapid economic growth (e.g., see Choi \& Ang, 2003). Specifically, in China, energy efficiency continued to improve 
due to technology development through 1980's and 90' although in the early 2000's China experienced deterioration of energy efficiency because of rapid growth of energy intensive industries including cement and steel at both the country and regional levels (Fisher-Vanden et al., 2006; Liao et al., 2007; Ma \& Stern, 2008; Zhao et al., 2010; Hara et al., 2011). More recently, China's overall energy intensity began to improve, but rapid economic growth dissipated the positive effects resulting in increase in the total energy consumption (Yabar et al., 2010).

However, those studies tend to ignore the heterogeneity of China in terms of development stages across provinces including industrial structure, income and technological levels, all of which affect energy consumption and productivity. One reason for this tendency is due to lack of data available for China. To implement decomposition analysis of energy productivity, for example, specific information on outputs in different sectors as well as on the corresponding energy use is necessary. Given the fact that the secondary sector including manufacturing and heavy industries are important sectors for China's economic development, owing energy efficiency changes only to industrial structure is insufficient as effective policy implications from the analysis. A few studies highlighted some of these points. Hu and Wang (2007) estimated energy efficiency of Chinese provinces, arguing that a U-inverted relationship exists between energy efficiency and economic development due to industrial structure changes in the development process. Fisher-Vanden et al. (2006) used a firm level data set to show availability of energy resource affect energy productivity. It is yet essential to understand the mechanism of how energy productivity is determined in a systematic way in order to draw useful information for effective policy making.

In particular, this paper employ a growth accounting method, a widely used method for technology level estimation in the economic literature requiring less amount of information than other methods, to examine the determinants of energy use and technological levels. Provincial data are used to estimate the energy productivity and technology level and then examine what factors determine the level of technology. The results of the analysis quantitatively shows that energy productivity is determined by 1) technology level that is attributed to past investment and education, and 2) input factors' effect that is influenced by industrial structure. Specifically, our estimation shows that disparity in energy productivity level exists across provinces even after controlling for differences in the industrial structure. Also, we confirmed that the above two factors affect the level of energy technology using regression analysis. Particularly, education and foreign direct investment in addition to the conditions of energy supply and demand are found to be important factors. These results indicate that the creation of right incentives including setting appropriate energy prices is of particular importance to induce investment in energy technologies.

\section{Estimation of Energy Productivity and Technology}

\subsection{Growth Accounting: Decomposing Energy Productivity}

We apply the growth accounting method developed by Robert Solow (Solow, 1957) to calculate energy technology level for Chinese provinces. Assume the aggregate production function for a province is of a Cobb-Douglas type in which labor, capital stock, and energy are input factors:

$$
Y_{i}=A L_{i}^{\alpha} K_{i}^{\beta} E_{i}^{\gamma}
$$

where $\mathrm{Y}$ is gross regional product (GRP), $\mathrm{K}$ is capital stock, $\mathrm{L}$ is labor, and $\mathrm{E}$ is energy input. The parameters $\alpha$, $\beta$, and $\gamma$ are elasticity of labor, capital and energy input factors, respectively. A in the production function is technological level (also referred to as total factor productivity or TFP): even if all the inputs factors are constant, increase in A leads to larger output.

This production function is assumed to exhibit constant returns to scale (CRS). So, divide both sides by E to obtain:

Take then a log to have:

$$
Y_{i} / E_{i}=A_{i}\left(L_{i} / E_{i}\right)^{\alpha}\left(K_{i} / E_{i}\right)^{\beta}
$$

$$
\ln \left(Y_{i} / E_{i}\right)=\ln A_{i}+\alpha \ln \left(L_{i} / E_{i}\right)+\beta \ln \left(K_{i} / E_{i}\right)
$$

The interpretation of Equation (3) is as follows. The left hand side of Equation (3) is log of energy productivity and the right hand side shows energy productivity can be decomposed into three parts. The second and the third terms of the right hand side are respectively the contribution of per energy-use unit of labor and capital inputs to energy productivity. That is, other inputs including energy being unchanged, more labor inputs can increase energy productivity at the economy level.

The first term of the right hand side, $\ln$ A (or TFP), represents the technology level for energy productivity in that 
it captures the contribution to energy productivity that is unexplained by the ones of physical factor inputs. Although TFP can be thought of as a technological level as explained earlier, it captures also the effects of any other factors such as the know-how of efficient energy use (Farmer, 2002; Hayami, 1995). In reality no data on A exists. However, with given Equation (3), TFP levels for each province can be calculated as a residual by taking a difference between output and input contributions because data on the output, capital stock, labor, and energy use for each province are available (Solow, 1957).

\subsection{Data and Parameter Values for the TFP Estimation}

All data used for the TFP estimation are obtained from a series of China Statistical Yearbooks (years of 2000, 2001, 2002, and 2004-2007) and China Energy Statistical Yearbooks (years of 2004-2007). We first notice that throughout the analysis, Tibet and Chongqing are excluded due to a large number of missing data. As a result, our data set contains 116 observations from 2004-2007 with 29 provinces in each year.

The output is GRP from 2004 to 2007 of which values are adjusted at constant prices of 2004 as a base year. As for energy, total energy consumption is used. Ideally, total energy input for production sectors should be used, but such data are not available at the regional level. We use the number of employment for labor forces.

Because of data limitation, we estimated capital stock from investment data using the perpetual inventory method (PIM). The PIM assumes that the evolution of capital stock depends on investment and the decay of old capital stock. With this assumption, the evolution of capital stock is expressed as:

$$
K_{i: t}=K_{i: t-1}-\delta K_{i \cdot t-1}+I_{i: t-1}
$$

where $\delta$ is a depreciation rate and I is investment. Given Equation (4), the capital stock in year $t$ can be approximated by:

$$
K_{i \cdot t}=I_{i \cdot t-1} / \delta+g_{i}
$$

where $g$ is the annual growth rate of investment level for province $i$. Once a capital stock level of year $t$ is determined, the capital stock in the following years $(t+1, t+2)$ can be calculated according to Equation (4). In the estimation, we assume that $\delta=0.07$ (i.e., seven percent decay rate per year). Regarding investment data, we use gross capital formation as investment data from 1999 to 2008. The gross capital formation values are adjusted using price indices of fixed asset obtained from Chinese Statistical Yearbooks, in which 2004 price is used as a base. From this data series, we then calculated annual growth rates of investment for each province. The average of investment growth rate for all the region was 16.8 percent.

Table 1. Descriptive statistics of input and output variables, mean and standard deviation

\begin{tabular}{ccccc}
\hline & 2004 & 2005 & 2006 & 2007 \\
\hline GRP & 5529.7 & 6257.0 & 7117.7 & 8139.4 \\
million Yuan & $(4379.8)$ & $(5007.1)$ & $(5746.4)$ & $(6585.9)$ \\
Labor & 2223.6 & 2281.6 & 2337.5 & 2393.4 \\
10000 persons & $(1481.2)$ & $(1532.7)$ & $(1571.4)$ & $(1611.9)$ \\
Capital stock & 11887.7 & 13687.9 & 15858.3 & 18495.5 \\
million Yuan & $(9842.3)$ & $(11173.5)$ & $(12774.1)$ & $(14613.8)$ \\
Energy & 7832.7 & 8903.6 & 9812.2 & 10743.8 \\
10000 TCE & $(4770.9)$ & $(5613.7)$ & $(6208.0)$ & $(6804.7)$
\end{tabular}

Note: Each year contains 29 observations (provinces). The total number of observations $(N)$ is thus 116 . Standard deviation is in parenthesis.

The descriptive statistics of GRP, labor, capital stock, and energy of 29 provinces in 2004-2007 are reported in Table 1. During the period, all the variables increased. Particularly, the growth rates of GRP, capital stock, and energy consumption during the period are 47 percent, 56 percent, and 37 percent, respectively. At the same time, it is observed that standard deviations of each variable increased during the period, indicating income disparities between provinces became larger.

Finally, regarding parameter values of the production function, we assume the elasticity of labor input is 0.4 $(\alpha=0.4)$. Given the CSR assumption, the sum of the capital and energy input shares should then be 0.6 , and we 
set the capital share as $0.55(\beta=0.55)$, and the energy input share as $0.05(\gamma=0.05)$. To obtain the robustness of our study, we also demonstrated the same procedure as in what follows with using parameter values; $\alpha=0.4 ; \beta=0.57$, and $\gamma=0.03$; and the corresponding results did not change very much.

\section{Analysis of Energy Productivity Determinants}

\subsection{Energy Productivity Versus Energy Technology}

In this section, we first show energy productivity for Chinese provinces through 2004 and 2007 to clarify the difference between energy productivity and energy technology. Figure 1 presents energy productivity, the ratio of GRP and energy input (inverse of energy intensity). The results show that overall energy productivity increased during the period. Also, it is shown that there is a large difference in productivity between provinces. Particularly, developed provinces like Shanghai Jiangsu, and Zhejiang are likely to have high energy productivity.

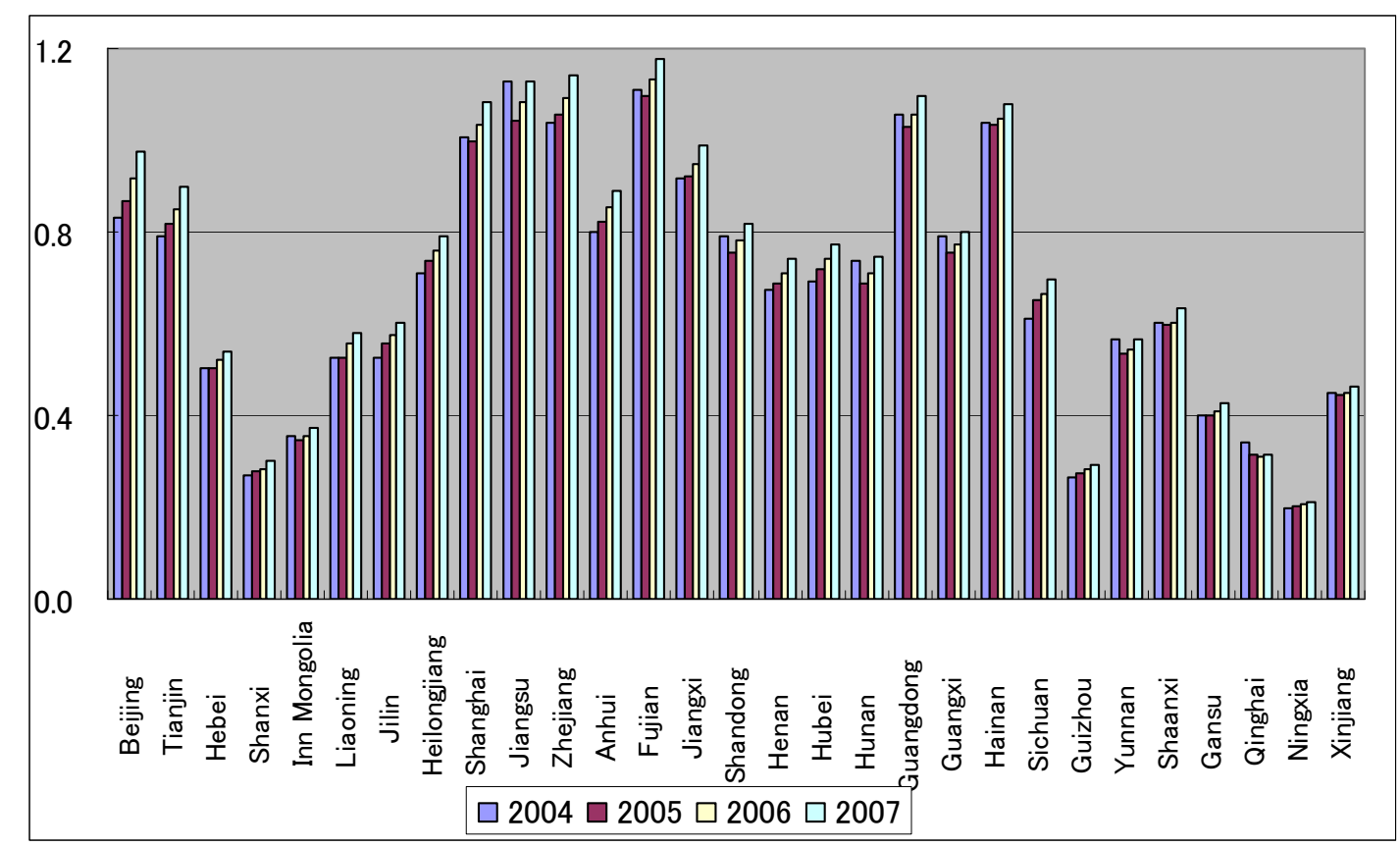

Figure 1. Energy productivity of China's 29 Provinces, 2004-2007

To the contrary, provinces that are experiencing rapid economic growth through the development of heavy industry and less developed provinces tend to show low energy productivity. The first includes Hebei, Shanxi, Inner Mongolia, and Liaoning, and the latter includes Guizhou, Guanxi, and Ningxia. Regarding the first group, the share of the secondary industry to GRP in Hebei, Shanxi and Inner Mongolia in 2008 were respectively 0.54, 0.64 , and 0.55 while its national average was 0.48 (NBSC, 2009a). Meanwhile, per capita GRP of Guizhou, Guanxi, and Ningxia in 2008 were 8000 Yuan, 14800 Yuan, and 17700 Yuan, respectively, which are much lower than the national average, 24000 Yuan (all are the current price at 2008) (NBSC, 2009a). 


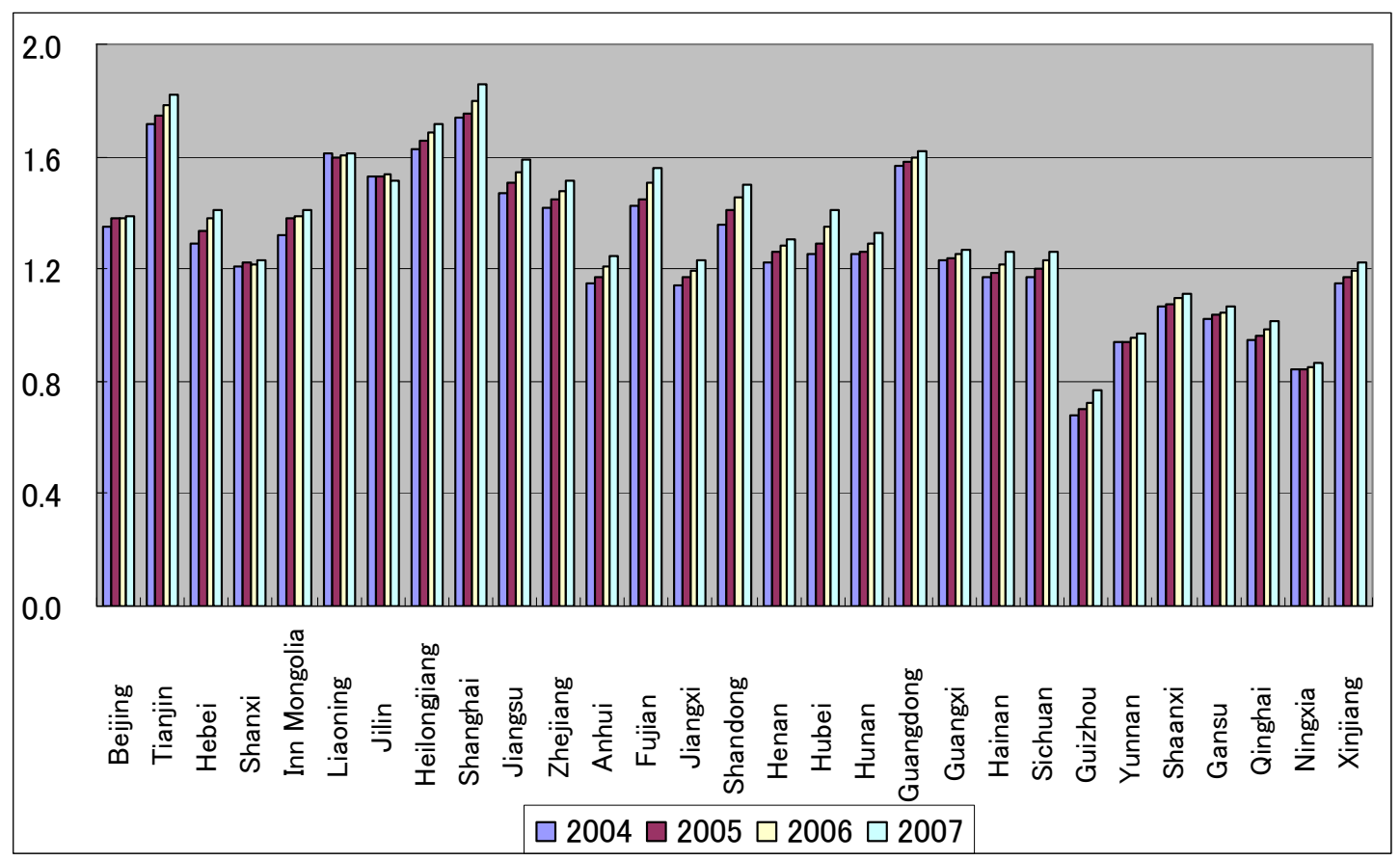

Figure 2. TFP (energy technology) levels of China's 29 Provinces, 2004-2007

Figure 2 shows TFP levels of 29 provinces from 2004 to 2007, which are calculated from the data in Table 2 with Equation (3). Generally, these values have similar patterns to the energy productivity results: TFP values tend to increase over time and under-developed provinces such as Guizhou, Guanxi, and Ningxia are likely to show poor performance. Figure 3 in fact shows that there is a clear positive association between TFP level and energy productivity. This observation indicates that energy technology is a significant source of achieving high energy productivity.

Table 2. Correlation of energy productivity, TFP and economic characteristics based on ordinary least squares

\begin{tabular}{ccc}
\hline & \multicolumn{2}{c}{ Dependent variables } \\
& $Y / E$ & $\ln A$ \\
\hline Share of secondary sector & $-{ }^{* * *}$ & $+* * *$ \\
GRP per capita & $+* * *$ & $+* * *$ \\
\hline$N=116$ & Adj $R^{2}=0.35$ & Adj $R^{2}=0.45$ \\
F-statistics & $31.03^{* * *}$ & $89.22^{* * *}$ \\
\hline
\end{tabular}

Note: $* * *$ denotes statistical significance at the $1 \%$ level.

Yet, comparison of energy productivity and technology levels also reveals different insights between the two indicators. For example, with respect to energy productivity industrialized provinces in the Northern China such as Inner Mongolia, Jilin, and Heilongjiang tend to show poor performance while TFP levels of these provinces are above the average. To make sure, we demonstrate a simple regression analysis to show how industrial structure and GRP per capita are correlated with energy productivity and TFP levels. The regression results with using the same sample observations as in the TFP estimation are reported in Table 2. Both GRP per capita and the ratio of the secondary sector's value-added to the total GRP are statistically significant in the two estimated equations. However, the estimated coefficients of the ratio of secondary sector have different signs: larger share of secondary industry has an adverse effect on energy productivity, but it is positively associated with technology levels. The results indicate the mechanisms of how each performance is made are different. Therefore, to examine the sources of the development of energy technology is of importance. 


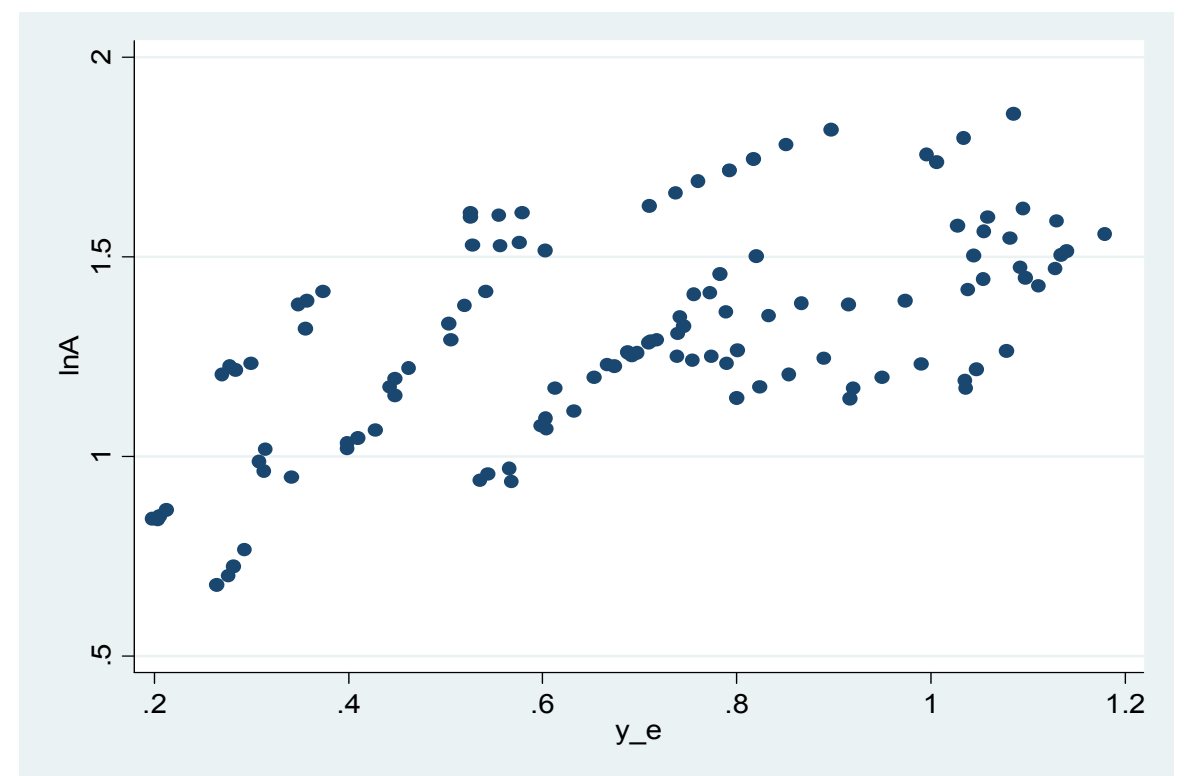

Figure 3. Energy productivity $(y / e)$ versus TFP $(\ln A)(N=116)$

\subsection{Determinants of Technology Level}

\subsubsection{Factors that Determine Technology Level}

In this subsection, we propose the structure of how economy-wide energy productivity is determined (Figure 4). As shown by the growth accounting, energy productivity is decomposed into technology and physical input parts. We then raise two main factors as the determinants of technological level as a hypothesis. First, we claim that one of the main determinants of technology level is research and development (R\&D). R\&D is the source of creation of new technologies including more energy-efficient equipments and systems (Freeman \& Soete, 1997; Ruttan, 2001). Particularly, even when the industrial structure and other factors are unchanged within the region, energy productivity is hardly improved without introducing new technologies. Second, we hypothesize that the quality of input factors (labor and capital) influences on the technology level. Notice that TFP is measured as a residual of energy productivity and the contribution of input factors (See Equation (3)). However, these contributions ignore the quality of each input factor. As an example, when workers are more knowledgeable, the economy is probably able to use input resources (including energy) more efficiently. Likewise, the quality of capital is significant for better use of input resources. These effects are to be captured by TFP. As for the quality of labor input, we used the number of students in higher education per 10,000 people in each province.

In order to confirm our claim, we demonstrate regression analysis in which TFP of the 29 provinces in 2004-2007 is used as an un-explanatory variable. As for the independent variables, we used the ratio of investment in technology update in the energy sector to the total GRP in 2000-2003 for R\&D. We used the past investment data because there is typically a time lag between investment and creation/diffusion of new technologies. We assume that the higher the rate of investment is, the larger the TFP value is. As the quality of capital is hard to estimate, we use the share of foreign direct investment (FDI) as a proxy for the quality of capital input. The logic behind our claim is that when foreign companies make investment abroad, they presume that they possess more advanced technologies and better know-how than the domestic companies do. In fact, empirical analysis for China showed FDI is an effective way to introduce advanced technology into the region (Liu \& Wang, 2003). We expect positive effects of education and FDI variables on TFP. 


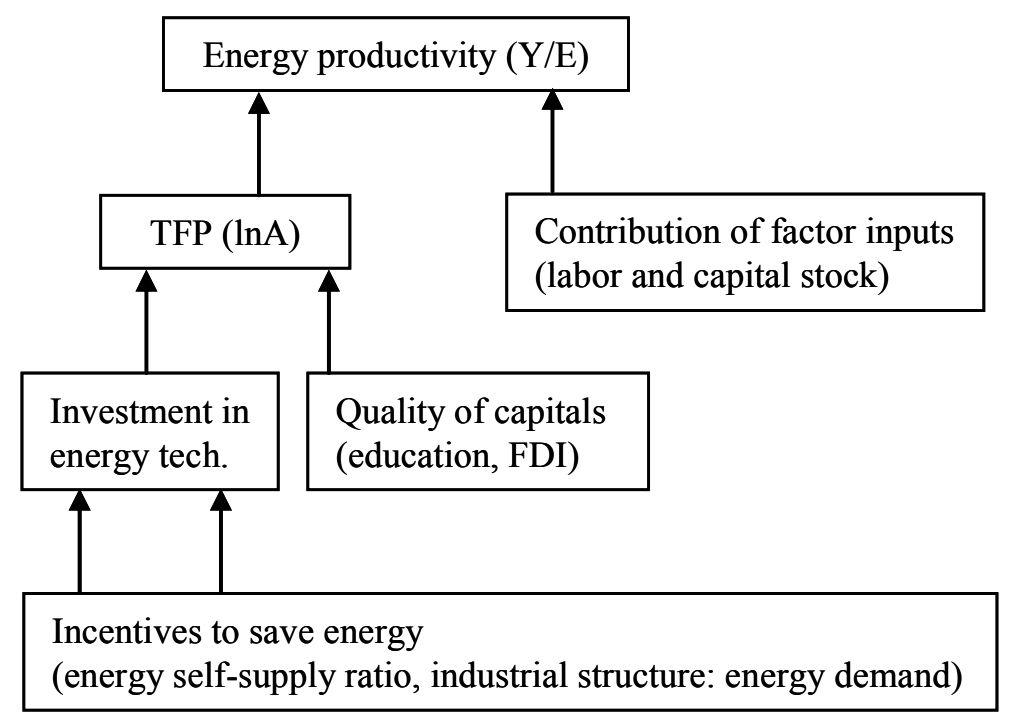

Figure 4. How economy-wide energy productivity level is determined

Our model specification has technical issues, however. Since our data set is of panel (i.e., cross-section and chorological), we employed the fixed effect model in which each year is considered to have fixed effects. Furthermore, in our model specification, there is possibility that investment in energy technology is an endogenous variable. That is, the investment level is endogenously determined by other factors. Specifically, conditions of energy supply and demand potentially affect incentives to save energy and thus investment in energy technology. If it is the case, the regression estimates will be biased. One method to deal with this issue is the instrument variables (IV) regression (Wooldridge, 2002), in which we first estimate a regression equation for investment in 2000 and then we use the estimated values of investment instead of the real values for the fixed effect model estimation. The practical problem is how to find instrument variables. We decided to use the share of secondary sector in GRP and energy sufficiency rate for each province in year 2000. These variables represent the conditions of energy supply and demand in the region, thereby influencing the incentive to save energy use. These variables are theoretically uncorrelated with the TFP level in 2004-2007 and thus can be used as IVs, which is technically required in order to obtain unbiased estimates.

\subsubsection{Regression Results}

Table 3 reports the regression results of the IV-Fixed effect and the simple fixed-effect estimations. Interestingly, the estimated coefficient in the IV fixed-effect model is positive and statistically significant while the one in the simple fixed-effect model is negative and statistically insignificant. The results suggest that we successfully correct the biasness generated by the endogenous issue. The positive sign of the energy investment in the IV-fixed model explains the effectiveness of investment in energy technology (made in the past) in increasing energy productivity. Also this result indicates that such investment was driven by the conditions of energy supply (resource endowment) and demand (industrial structure). The coefficients of the capital quality are also statistically significant with having expected signs. Provinces with educated workers tend to use energy use more efficiently, other things being equal. As well, inflow of FDI enhances the quality of capital stock in the region, eventually leading to higher energy productivity.

\section{Discussion}

This paper examined energy productivity for China's provinces. Employing the growth accounting method, which decomposes energy productivity into TFP (technology) and input factors parts, we estimated chronological TFP levels of 29 provinces. The paper showed a positive association between energy productivity and technological levels, suggesting technology is an important source of energy productivity growth. Further, we identified the determinants of TFP using econometric techniques. The finding was that the quality of capitals such as education level and FDI as well as the investment in energy technology have positive impacts on technology level. Behind the mechanism, it was also found that incentives to save energy including resource abundance and industrial structure induced investment in energy technology, thereby increasing energy productivity. 
Table 3. Regression results - determinants of technology level

\begin{tabular}{lll}
\hline & IV, Fixed-effect & Fixed-effect \\
\hline Energy investment & $0.185^{* * *}$ & -0.011 \\
Higher education & $0.020^{* * *}$ & $0.017^{* * *}$ \\
FDI & $0.0001^{* * *}$ & $0.0001^{* * *}$ \\
Constant & $0.746^{* * *}$ & $1.006^{* * *}$ \\
\hline$N=116$, & Overall $R^{2}=0.35$ & Overall $R^{2}=0.53$ \\
\hline
\end{tabular}

Note: $* * *$ denotes statistical significance at the $1 \%$ level. Instrument variables include energy sufficiency rate and the share of secondary industry to GRP.

These results can provide policy implications. As the results showed, creation of incentives to make investment eventually leads to increase in energy productivity. Although it can be regarded as costs on the surface, policy instruments that set appropriate energy prices plausibly induce innovation in the Chinese energy sector. In fact, evidence exists that price is a significant factor for technological innovation for energy in the US and Europe (Popp, 2002; Jaffe et al., 2002). Regarding China, the current prices on energy are still regulated by the government (Wang et al., 2009). However, an empirical study shows that raising energy prices could be an effective policy tool for increasing efficiency of energy use even in China (Hang \& Tu, 2007) and our results support their claim that policies for setting appropriate price are of vital importance. Moreover, creating an environment that facilitates the diffusion of better technologies is crucial for improving energy productivity. It is often reported that uncertainty of Chinese policies is the main barrier for foreign companies to make investment. Therefore, reducing political uncertainty and establishing appropriate environmental and price policies are key to achieving the balance between economic development and energy conservation.

Finally, although future research needs to investigate the current policy regarding energy and technological development in the energy sectors for China, the proposed energy productivity assessment system is well applicable to other countries and regions to draw useful implications for policy making as well. Moreover, in line with this, it is possible to make a comparison of energy productivity among countries which have different industrial structures in a more fair way. Particularly, for China which has now the world manufacturing center resulting in larger per GDP green house gas emissions, this sort of assessment system will produce different implications for the discussion of global warming.

\section{References}

Choi, K. H., \& Ang, B. W. (2003). Decomposition of aggregate energy intensity changes in two measures: ratio and difference. Energy Economics, 25, 615-624. http://dx.doi.org/10.1016/S0140-9883(03)00038-0

Farmer, R. E. A. (2002). Macroeconomics. Ohio, USA: South-Western Thomas Learning.

Feng, T., Sun, L., \& Zhang Y. (2009). The relationship between energy consumption structure, economic structure and energy intensity in China. Energy Policy, 37, 5457-5483. http://dx.doi.org/10.1016/j.enpol.2009.08.008

Fisher-Vanden, K., Jefferson, G. H., Ma, J. M., \& Xu, J. (2006). Technology development and energy productivity in China. Energy Economics, 28, 690-750. http://dx.doi.org/10.1016/j.eneco.2006.05.006

Freeman, C., \& Soete, L. (1997). The economics of industrial innovation (3rd ed.). Cambridge, Massachusetts: MIT Press.

Jaffe, A. B., Newell, R. G., \& Stavins, R. N. (2002). Environmental policy and technological change. Environment \& Resource Economics, 22, 41-69. http://dx.doi.org/10.1023/A:1015519401088

Hang, L., \& Tu, M. (2007). The impacts of energy prices on energy intensity: Evidence from China. Energy Policy, 35, 2978-2988. http://dx.doi.org/10.1016/j.enpol.2006.10.022

Hara, K., Yabar, H., Uwasu, M., \& Zhang H. (2011). Energy intensity trends and scenarios for China's industrial sectors - A regional case study. Sustainability Science, 6, 123-134. http://dx.doi.org/10.1007/s11625-010-0125-x

Hayami, Y. (1995). Development Economics. Tokyo: Sobun-sha.

He, Y., Lao, G. H., Osuch, C. E., Zuo, W. R., \& Wen B. F. (2008). Co-integration-based analysis of energy 
assurance for steady economic growth in China. Journal of China University of Mining \& Technology, 18, 250-254. http://dx.doi.org/10.1016/S1006-1266(08)60053-X

Hu, J. L., \& Wang, S. C. (2006). Total-factor energy efficiency of regions in China. Energy Policy, 34, 3206-3217. http://dx.doi.org/10.1016/j.enpol.2005.06.015

Liao, H., Fan, L., \& Wei, Y. M. (2007). What induced China's energy intensity to fluctuate: 1997-2006? Energy Policy, 35, 4640-4649. http://dx.doi.org/10.1016/j.enpol.2007.03.028

Liu, X., \& Wang, C. (2003). Does foreign direct investment facilitate technological progress?: Evidence from Chinese Industries. Policy Research, 32, 945-953. http://dx.doi.org/10.1016/S0048-7333(02)00094-X

Ma, C., \& Stern, D. (2008). China's changing energy intensity trend: A decomposition analysis. Energy Economics, 30, 1037-1053. http://dx.doi.org/10.1016/j.eneco.2007.05.005

National Bureau of Statistics of China (NBSC). (2009a). China Statistical Yearbook 2008. Beijing: China Statistics Press.

National Bureau of Statistics of China (NBSC). (2009b). China Energy Statistical Yearbook 2008. Beijing: China Statistics Press.

Popp, D. (2002). Induced innovation and energy prices. American Economic Review, 92, 160-180. http://dx.doi.org/10.1257/000282802760015658

Ruttan, W. V. (2001). Technology, growth, and development- An induced innovation perspectives. New York: Oxford University Press.

Solow, R. M. (1957). Technical change and the aggregate production function. Review of Economics and Statistics, 39, 312-320. http://dx.doi.org/10.2307/1926047

Wang, Q., Qiu, H. N., \& Kuang, Y. (2009). Market-driven energy pricing necessary to ensure China's power supply. Energy Policy, 37, 2498-2504. http://dx.doi.org/10.1016/j.enpol.2009.03.008

Wooldridge, W. J. (2002). Econometric analysis of cross section and panel data. Cambridge, Massachusetts: The MIT Press.

The World Bank. (2010). World Development Indicators, http://data.worldbank.org/indicator. (July, 2010)

Yabar, H., Uwasu, M., Hara, K., \& Zhang, H. (2009). Scenarios to design a resources-circulating society in Asia; Case study in yangtze delta industrial sector. Proceedings of the 6th International Symposium on Environmentally Conscious Design and Inverse Manufacturing, 565-570.

Yuan, J. H., Kang, J. G., Zhao, C. H., \& Hu, Z. G. (2008). Energy consumption and economic growth: evidence from China at both aggregated and disaggregated levels. Energy Economics, 30, 3077-3094. http://dx.doi.org/10.1016/j.eneco.2008.03.007

Zhao, X., Ma, C., \& Hong, D. (2010). Why did china's energy intensity increase during 1998-2006: decomposition and policy analysis. Energy Policy, 38, 1379-1388. http://dx.doi.org/10.1016/j.enpol.2009.11.019 